\title{
Blood lactate changes during exercise at high altitude
}

\author{
N. Binns, A.D. Wright, B.M. Singh, J.H. Coote and A.R. Bradwell \\ Departments of Medicine and Physiology, University of Birmingham, Birmingham, UK.
}

\begin{abstract}
Summary: Blood lactate concentrations were measured in 18 normal subjects at the end of an exercise test designed to maintain heart rate at $85 \%$ of maximum for 15 minutes. Blood lactate concentrations were reduced at high altitude $(4846 \mathrm{~m})$ and correlated positively with basal $\mathrm{pH}$ and negatively with basal $\mathrm{Pa}, \mathrm{O}_{2}$ levels. Blood lactate concentrations tended to be lower in those subjects on acetazolamide but were not correlated with the severity of acute mountain sickness or with the workload of the exercise test. We conclude that the $\mathrm{pH}$ changes are probably the most significant factor in reducing lactate concentrations.
\end{abstract}

\section{Introduction}

Increases in blood lactate concentration in response to exercise are enhanced by acute hypoxia ${ }^{1}$ but reduced by chronic hypoxia without any significant change in basal levels. ${ }^{2}$ At least four factors have been suggested to account for this effect of chronic hypoxia, including $\mathrm{pH}$ effects on rate limiting enzymes of the glycolytic pathway such as phosphofructokinase, diminution in muscle glycogen and a greater use of free fatty acids, slower release of lactate, and a reduction in muscle blood flow. ${ }^{3}$

In this study we assessed the effect of acetazolamide treatment and the resulting changes in $\mathrm{pH}$ and blood gases on the blood lactate response to exercise at high altitude.

\section{Methods}

Eighteen normal subjects ( 9 on placebo and 9 on acetazolamide $500 \mathrm{mg}$ /day) walked to $4846 \mathrm{~m}$ over 11 days. ${ }^{4}$ Exercise studies were carried out after they had stayed at $4846 \mathrm{~m}$ for 2 to 4 days. Subjects were tested at least 90 minutes after any food. Exercise testing on a bicycle ergometer was designed to maintain heart rate at $85 \%$ of maximum for 15 minutes. ${ }^{5}$ Venous blood was taken just before the start and at the end of exercise and pipetted immediately into $5 \%$ perchloric acid. Samples were kept at ambient temperature and blood lactate measured by a lactate dehydrogenase method on return to Birmingham. Arterialized capillary blood was taken for blood gas measurements ${ }^{6}$ before exercise. Acute mountain sickness was assessed by a peer review method in which

Correspondence: A.D. Wright M.B., F.R.C.P., The General Hospital, Steelhouse Lane, Birmingham B4 6NH, UK. subjects ranked all members of the expedition on a $20 \mathrm{~cm}$ line. ${ }^{7}$ Eight of the subjects performed similar exercise testing at sea level at a work load to give $85 \%$ of maximum heart rate but without acetazolamide.

\section{Results}

Blood lactate response to exercise a high altitude was reduced in all subjects. The mean ( \pm s.d.) concentration at the end of exercise at high altitude was $2.7 \pm 1.0 \mathrm{mmol} / 1$ compared with $5.9 \pm 2.6 \mathrm{mmol} / 1$ at sea level $(P<0.01$, paired $t$ test $)$. Blood lactate concentrations at the end of exercise at high altitude

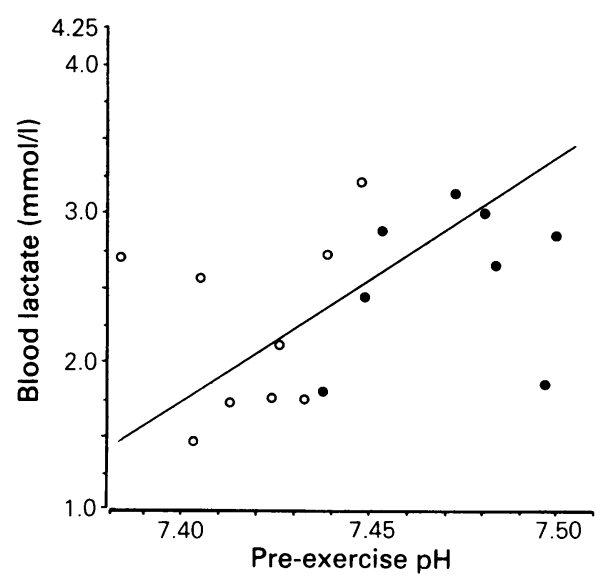

Figure 1 The blood lactate concentrations at the end of exercise at high altitude and pre-exercise arterialized capillary $\mathrm{pH}(r=+0.52, P<0.05)$. Subjects on placebo; $O$, subjects on acetazolamide.

(C) The Fellowship of Postgraduate Medicine, 1987 
were not significantly different in subjects on acetazolamide $(2.2 \pm 0.6 \mathrm{mmol} / \mathrm{l})$ compared with those on placebo $(2.8 \pm 0.8 \mathrm{mmol} / \mathrm{l}) \quad(P<0.2$, unpaired $t$ test). However, blood lactate concentrations at the end of exercise correlated with both the pre-exercise $\mathrm{pH}(r=+0.52, P<0.05$; Figure 1$)$ and pre-exercise $\mathrm{Pa}, \mathrm{O}_{2}(r=-0.55, P<0.02)$.

Blood lactate concentrations did not correlate with severity of acute mountain sickness or with the workload achieved during the test (Wilcoxon rank order test).

\section{Discussion}

Our results confirm that there is a reduction in blood lactate concentrations on exercising at high altitude ${ }^{2,8}$ and suggest that of the various mechanisms proposed.

\section{References}

1. Sutton, J.R. Effect of acute hypoxia on the hormonal response to exercise. J Appl Physiol 1977, 42: 487-592.

2. Young, A.J. Evans, W.J., Cymerman, A., Pandolf, K.B., Knapik, J.J. \& Maher, J.T. Sparing effect of chronic high altitude exposure on muscle glycogen utilization. $J$ Appl Physiol 1982, 52: 857-862.

3. Boutellier, U., Howald, H., DiPrampero, P.E., Giezendanner, D. \& Cerretelli, P. Human muscle adaptations to chronic hypoxia. In: Sutton, J.R., Houston, C.S. \& Jones, N.L. (eds) Progress in Clinical and Biological Research Vol. 136. Hypoxia, Exercise and Altitude. Proceedings of the 3rd Banff International Hypoxia Symposium. Alan R. Liss Inc., New York, 1983, pp. 273-281.

4. Bradwell, A.R. \& Coote, J.H. The BMRES 1984 Medical Research Expedition to the Himalayas. Postgrad Med J 1987, 63, 165-167.

5. Bradwell, A.R., Dykes, P.W., Coote, J.H. et al. Effect of the $\mathrm{pH}$ changes are the most important. This is consistent with the striking reduction in lactate con- $\frac{3}{0}$ centrations in normal subjects exercising whilst $\varrho$ acidotic on ammonium chloride. ${ }^{7}$ Our subjects were. not acidotic under basal conditions but $\mathrm{pH}$ levels were not measured during exercise. It might be expected that the acetazolamide group, having higher hydrogen ion concentrations than the placebo group would have had lower lactate responses. This trend was present but not significant with the relatively small numbers involved. The reduction in workload during the test of ${ }^{\infty}$ approximately $30 \%$ at high altitude and may have $\vec{\circ}$ contributed to the lower lactate concentrations. However, the reduction in lactate concentrations was more than $50 \%$ compared with sea level. There was no evidence of any relationship between the severity of acute mountain sickness and the blood lactate concentrations.

acetazolamide on exercise performance and muscle mass $\stackrel{5}{-}$ at high altitude. Lancet 1986, i: 1001-1005.

6. Milles, J.J., Chesner, I.M., Oldfield, S. \& Bradwell, A.R. ฏ Effect of acetazolamide on blood gases and 2.3 DPG $\frac{\widehat{\rho}}{\supset}$ during ascent and acclimatization to high altitude. Post grad Med J 1987, 63, 183-184.

7. Fletcher, R.F., Wright, A.D., Jones, G.T. \& Bra\& well, A.R. The clinical assessment of acute mountam sickness. $Q J$ Med 1985, 54: 91-100.

8. Cerretelli, P., Veicsteinas, A. \& Marconi, C. Anaerobic metabolism at high altitude: the lactacid mechanism. In: Brendel, W. \& Zink, R.A. (eds) High Altitude Physiology and Medicine, Springer-Verlag, New York, 1982, pp. 94 102.

9. Jones, N.L., Sutton, R.J., Taylor, R. \& Toews, C.J. Effect of $\mathrm{pH}$ on cardiorespiratory and metabolic responses to exercise. J Appl Physiol 1977, 43: 959-964. 